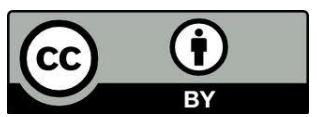

\title{
O Ensino Religioso no Estado de Alagoas
}

\author{
Religious Education in the state of Alagoas \\ Ângela Maria Ribeiro Holanda \\ Pedagoga, especialista em ensino religioso, compõe a equipe técnica pedagógica da Gerência de Ensino \\ Fundamental da Secretaria de Estado de Educação e do Esporte de Alagoas. \\ ribeiroholanda@gmail.com
}

RESUMO: O presente artigo apresenta o percurso histórico do ensino religioso na rede estadual de Alagoas, da concepção confessional até a compreensão de área de conhecimento, destacando os decretos, leis, pareceres e resoluções estaduais e nacionais que regulamentam esse ensino. Apresenta ainda a ênfase atribuída a esse ensino em diferentes épocas, às orientações referentes à sistemática desse ensino; em sua essência, a seleção dos conteúdos, os requisitos para a escolha, a indicação e a metodologia do trabalho pedagógico dos professores. Trata-se de uma narrativa processual de abordagem colaborativa possibilitando conhecer e rememorar os diferentes instrumentos que foram determinantes para a efetivação desse componente curricular nas unidades escolares do sistema de ensino de Alagoas.

Palavras-chave: Ensino religioso; Componente curricular; Área de conhecimento.

ABSTRACT: This article presents the historical way of the Religious Teaching in its network in Alagoas; from the confessional conception until the knowledge area, highlighting the enactment, laws, reports and local and national declarations, that establish rulers for teaching. It also presents the enphasis acredited in diferent moments of its history, in the guidelines and references of the teaching system; in its basis, the selection of contents, the requirements for choicing the subjects and the methodology of teaching work. It is a processual narrative in a colaborative approach allowing to know and to get back the diferent instruments that were a determined procedure to construct curricular components of the schools in tha teaching system in Alagoas.

Keywords: Religious teaching; Curricular components; Knowledge area 


\section{Introdução}

O relato do ensino religioso no Estado de Alagoas recupera os caminhos percorridos e os atores sociais desse processo e as legislações que foram determinantes para a sua inserção no currículo escolar das escolas públicas de Alagoas.

A participação da Igreja Católica Apostólica Romana foi imprescindível na efetivação da implantação desse ensino no currículo escolar das escolas públicas estaduais e municipais, embora direcionasse para a forma confessional católica e para a educação da fé dos/as estudantes.

Assim, esse artigo enfatiza a caminhada e diferentes percursos trilhados pelo ensino religioso, sinalizados pelas Leis, Decretos Governamentais, Estatuto do Ensino Religioso do Estado de Alagoas, Constituição Federal de 1988, LDB, Lei no 9.394/96, Lei no 9.475/97, Leis Orgânicas, Resoluções e Pareceres Nacionais, Estaduais e Municipais, Programação Mínima da Confissão Católica para o Ensino Religioso no Estado de Alagoas, Sistemática do Ensino Religioso para as Escolas Públicas, Conteúdos Curriculares, Formação de Professores, Estadualização da Lei no 9.475/97, e por último, as considerações gerais para a sua implantação/implementação no sistema de ensino de Alagoas.

\section{Histórico}

A implantação/implementação do Ensino Religioso, nas escolas públicas do Estado de Alagoas, passou por diferentes fases, a exemplo de outros Estados, iniciando na forma confessional católica até chegar à compreensão de área de conhecimento, atendendo aos dispositivos legais que regulamentam a educação básica no Brasil, e, desta feita sob a responsabilidade dos sistemas de ensino.

Há registros na história da educação de Alagoas que o ensino religioso era regido pelo Estatuto do Conselho do Ensino Religioso elaborado pela Arquidiocese de Maceió com vigência de cinco anos, assinado em 20 de fevereiro de 1944 pelo Arcebispo Metropolitano Dom Ranulpho e tinha como finalidade programar, orientar, inspecionar e desenvolver este ensino na Arquidiocese de Maceió. Nesse mesmo ano foi instituído pelo Interventor Federal do Estado de Alagoas, o Decreto Lei no 2.937, de 29 de maio, dispondo sobre o ensino religioso nos estabelecimentos de instrução primária 
do Estado de Alagoas que foi publicado no Diário Oficial do Estado, em 31 de maio de 1944.

Observa-se que os procedimentos adotados nesse estatuto estão em consonância com o art. 113 da Constituição do Brasil de 1937 e nas Leis Orgânicas do Ensino Normal e do Ensino Primário de 1946 que tratam sobre a inserção do ensino religioso nas escolas primárias, "nos cursos de primeiro e segundo ciclos do ensino normal". Nesse período os programas e os aspectos didáticos eram estabelecidos pela autoridade eclesiástica da igreja católica apostólica romana.

No ano de 1976, o ensino religioso é "disciplinado no Estado de Alagoas” pela Resolução $n^{\circ}$ 08, de 06 de março do Conselho Estadual de Educação, pelo Conselheiro Luiz Medeiros Netto. O art. $1^{\circ}$ expressa que este ensino "constituirá disciplina dos horários normais das Escolas Estaduais e Municipais do $1^{\circ}$ e $2^{\circ}$ Graus do Estado de Alagoas". Essa resolução atribuía ao sistema de ensino a distribuição da carga horária. E, em relação aos docentes, estabelece habilitação para o exercício do magistério, ter curso especializado de religião, de preferência Teologia e ser registrado pela autoridade religiosa competente. E os conteúdos a serem ministrados em sala de aula estariam sob a responsabilidade da "maior autoridade Estadual de cada confissão religiosa". A única confissão credenciada, a Católica Apostólica Romana.

Também nesse mesmo ano, é elaborado o Programa Mínimo da Confissão Católica para o Ensino Religioso do $1^{\circ}$ Grau, no Estado de Alagoas, sob responsabilidade da coordenação central do ensino religioso da Arquidiocese de Maceió e respaldado pelo Arcebispo Metropolitano, Dom Miguel Fenelon Câmara. Entre o que foi determinado nessa resolução, nas questões referentes aos conteúdos não há registros que outras confissões religiosas tenham participado do processo de elaboração do “programa mínimo" ou, que tenha apresentado o seu programa de ensino a Secretaria de Educação para o devido credenciamento. Daí, a presença, de apenas uma confissão religiosa.

Surge então o primeiro documento orientador da prática pedagógica, estruturado por faixa etária e características psicológicas, encaminhando os/as estudantes para o aprofundamento da fé, considerando que a ênfase e o objetivo do ensino religioso nesse período, eram "educar o aluno a colocasse diante do problema religioso e a dar a sua resposta devidamente informada, responsável e engajada". 
Observa-se que a citada resolução surge a partir da segunda Lei de Diretrizes e Bases da Educação Nacional, Lei n ${ }^{\circ}$ 5.692/71 e em conformidade com as determinações do parágrafo único do art. $7^{\circ}$ que trata sobre a forma de como será ministrado este ensino nas escolas públicas: "o ensino religioso de matrícula facultativa constituirá disciplina dos horários normais dos Estabelecimentos Oficiais de $1^{\circ}$ e $2^{\circ}$ Graus".

Além dessa resolução, há o Decreto do Governo Guilherme Palmeira nº 5.027, de 11 de março de 1982, considerando a citada lei e os mencionados, parágrafo e artigo que determinam a implantação do ensino religioso, de matrícula facultativa, compondo obrigatoriamente o currículo do ensino de $1^{\circ}$ e $2^{\circ}$ graus, devendo constar dos horários normais das escolas públicas da rede estadual, ministrado de acordo com a confissão religiosa do aluno.

Nesse decreto há um indicativo para o não proselitismo afirmando que, ao professor é extremamente proibido fazer, dentro da sua sala de aula, propaganda de qualquer credo ou confissão religiosa no sentido de influenciar os/as estudantes para aceitação do credo que professa. Entre outras atribuições legais, o decreto responsabilizava à autoridade eclesiástica ou religiosa, registrar, indicar e dispensar o professor do ensino religioso, além de estabelecer que cada credo ou confíssão, mediante a autoridade eclesiástica, credencie um representante junto à Secretaria de Educação com a responsabilidade de programar as atividades curriculares, envolvendo planejamento, execução e avaliação. 
O enfoque dessa orientação pedagógica estruturado na linha da confissão católica justificava-se segundo os gestores devido a uma pesquisa realizada em 1975 sobre "crenças religiosas", de cada estudante, realizada em quinze escolas estaduais localizadas na cidade de Maceió, destacando o percentual de 93\% católicos, 3\% pentecostais; $2 \%$ batistas, $1 \%$ presbiteriano e $1 \%$ pertencentes a outras crenças. Nesta pesquisa, aparece apenas, às denominações cristãs. Não se sabe se os/ estudantes que pertenciam às religiões, indígenas, africanas e orientais expressaram a sua confissão ou não se identificaram com medo de não serem aceitos, e, consequentemente excluídos. $\mathrm{Ou}$, por outro lado não há registros sobre a compreensão do significado de outras crenças ou até mesmo se de fato foram pesquisados. A própria expressão tem uma conotação excludente. A tendência da época sobre a concepção do ensino religioso se dava na forma confessional e, sobretudo nos destaques sobre os valores humanos e cristãos, o que constitui num aspecto positivo na perspectiva de uma escola que contribui para que homens e mulheres assimilem a cultura da solidariedade humana e da paz.

Nesse contexto, a Arquidiocese de Maceió e as Dioceses, de Penedo e Arapiraca através das paróquias apresentavam os possíveis candidatos/as a serem professores/as do ensino religioso na rede estadual e municipal de ensino. Os/as candidatos/as eram encaminhados à coordenação central para serem submetidos a uma avaliação.

Para tanto, eram apresentados requisitos para os possíveis professores/as, sendo, no entanto, exigido diploma do magistério público, participação em uma pastoral, e, de preferência, a catequese. Estes/as eram submetidos/as a uma avaliação e entrevista com conhecimentos doutrinários elaborados pela mencionada equipe constituída por professores pertencentes à Igreja Católica e do quadro efetivo do magistério público estadual. O/a candidato/a ao ser aprovado/a recebia uma declaração do Arcebispo afirmando que fora submetido ao teste de caráter doutrinário e, portanto, estava apto a exercer a função de professor/a, tornado-se assim, integrante do quadro do magistério público estadual. Em seguida, a relação dos que se encontravam aptos era encaminhada ao governo do estado para a devida nomeação. 
Havia outra forma de admissão de professores para ministrar as aulas de ensino religioso. Aqueles que já eram do quadro do magistério público, podiam fazer opção, porém eram submetidos aos mesmos procedimentos relacionados.

No art. $6^{\circ}$ desse decreto há uma afirmativa que a Secretaria de Educação ouvirá a autoridade religiosa para definição de conteúdos, decisão essa se assemelhando ao parágrafo $1^{\circ}$ do art. 33 , da Lei $n^{\circ} 9.475 / 97$ que dá nova redação ao art. 33 da Lei de Diretrizes e Bases da Educação Nacional.

\section{Conteúdos Curriculares /Currículo do Ensino Religioso}

Como eram os conteúdos curriculares nesse período? Além de assegurar o estudo respeitando a faixa etária e as características psicológicas, a proposta de estudo era distribuída entre objetivos educacionais, expressivos e comportamentais relacionando os conteúdos básicos e sugestões de atividades, por série/ano. A programação tinha como ponto de partida e como conteúdo "a própria existência, com o escopo de descobrir na própria vida a dimensão religiosa e ajudar os/as educandos/as a se abrirem para a resposta cristã". Tentava-se um ensaio na perspectiva do trabalho integrado, destacando em cada disciplina da base nacional comum, os múltiplos valores cristãos e as sugestões de atividades pedagógicas. Esta era uma forma de uma educação da fé através da vida escolar e das disciplinas.

Ainda sob a vigência do aludido Decreto surge em 1982 à primeira Proposta Curricular para o Ensino Religioso do Estado de Alagoas estruturado em quatro dimensões: pessoal, social, cósmica e religiosa, organizada por série/ano, com o mapeamento de conteúdos para a pré-escola, primeiro grau, segundo grau - científico ou básico e curso de formação do magistério de $1^{\circ}$ grau. Terminologias utilizadas na época.

Nessa lógica, iniciava-se um possível diálogo para com outras denominações, embora não mencionasse as religiões indígenas, africanas e orientais. O currículo resumia-se em boletins catequéticos da confissão católica considerando que o objetivo geral do ensino religioso estava voltado para a catequese na escola e para a maturidade da fé. 
Considerando que as leis e decretos normatizadores do ensino religioso, eram anteriores a Constituição Federal de 1988, privilegiando apenas uma denominação religiosa, e, portanto dissociadas das discussões atuais, a formação de professores/as, por sua vez, era consequentemente, voltada para a atuação catequética e não tinha um olhar plural para a diversidade religiosa brasileira e alagoana.

Com aprovação da Lei de Diretrizes e Bases da Educação Nacional, Lei $\mathrm{n}^{\circ}$ 9.394/96 art. 33, alterada pela Lei nº 9.475/97 várias providências deveriam ser tomadas, como exemplo a revisão da proposta curricular atualizando a forma de organização curricular, a fundamentação teórica e metodológica, os aspectos didáticos e avaliativos, atendendo aos princípios e fins da educação brasileira conforme artigo $3^{\circ}$ da referida legislação. A partir dessa Lei o ensino religioso passa a ser concebido como parte integrante da formação básica do cidadão constituindo disciplina dos horários normais das escolas públicas de ensino fundamental, assegurando respeito à diversidade cultural religiosa do Brasil, vedadas, quaisquer formas de proselitismo.

Pela própria complexidade do discurso sobre o ensino religioso, no contexto educacional brasileiro, quanto ao seu objeto de estudo, objetivo, conteúdo, metodologia, avaliação e formação dos/as profissionais, surge à necessidade da elaboração dos Parâmetros Curriculares Nacionais do Ensino Religioso, como instrumento que aponta referência, frente a uma discussão mais ampla sobre educação.

Em 1996, o MEC, divulgou os PCN de todas as áreas de conhecimento, deixando ausente o ensino religioso. Daí ocorre uma mobilização nacional efetuada pelo Fórum Nacional Permanente do Ensino Religioso para a inclusão de parâmetros para a citada disciplina, os quais foram elaborados coletivamente com educadores de diferentes tradições religiosas que juntos encontraram o que há de comum numa proposta educacional, que tem como objeto o Transcendente. Portanto, em 1997, como marco de um passo histórico da educação brasileira, surge o referencial e diretriz para o ensino religioso no Brasil: Parâmetros Curriculares Nacionais do Ensino Religioso.

Nesse sentido, em 1999 iniciou-se na rede estadual de ensino de Alagoas o processo de reelaboração da proposta curricular do ensino religioso, a partir das proposições da alteração do art. 33, devolvendo aos sistemas de ensino a responsabilidade de gerenciar este componente curricular, uma vez que aparece pela primeira na história da educação o ER área de conhecimento no conjunto dos demais 
componentes curriculares, conforme Resolução CEB/CNE $\mathrm{n}^{\circ}$ 02/98 e Parecer CEB/CNE 04/98. Para assessoria dos trabalhos contamos com a presença da Professora Especialista Lizete Carmem Viesser da cidade de Curitiba que dinamizou o estudo.

A dinâmica desse trabalho envolveu coordenadores do ensino religioso que atuavam nas coordenadorias regionais de ensino e na Secretaria de Estado da Educação e na Secretaria Municipal de Educação de Maceió. Nesse período podíamos contar com uma equipe pedagógica, coordenadores específicos do ensino religioso para participar e articular o processo.

Nas Coordenadorias de Ensino, na Secretaria de Educação e nas unidades escolares existia uma coordenação de ensino religioso. Esta era responsável pela dinamização e formação de professores/as nos municípios sede de CRE e nos municípios que compõem as referidas CREs. Essa organização funcionava, e, certamente foi o momento onde de fato ocorreu a formação de professores/as, ficando garantidos encontros mensais, nas primeiras terças feiras de cada mês, em todas as coordenadorias de ensino. Esta organização deixava o componente curricular com alguns privilégios e em alguns contextos foi motivo de resistência por parte dos gestores devido a essa prerrogativa, atribuída, somente, para esse componente curricular. O número de professores/as para atuar como coordenador/a e professor/a era numeroso, e, devido à carência de professores para assumir salas de aula nos anos iniciais do ensino fundamental, às vezes era impossível atender a essa organização.

Afinal, surge o Referencial Curricular do Ensino Religioso do Estado de Alagoas com a participação regional dos/as professores/as e dos coordenadores das duas redes de ensino, estadual e municipal. A organização desse referencial está em consonância com os eixos temáticos concebidos nos parâmetros curriculares nacionais e na Lei $n^{\circ} 9.475 / 97$. Pela falta de política para elaboração do currículo da educação básica no Estado de Alagoas este instrumento ficou em segundo plano e até desconhecido.

A situação atual, em termos de currículo da educação básica, no Estado de Alagoas é uma lacuna visto que o currículo existente ainda não contempla as legislações atuais e não envolve as etapas e modalidades de ensino com os respectivos componentes curriculares. Portanto, as dificuldades não são inerentes apenas ao ER, mas a educação, na sua íntegra. 
Atualmente há um movimento curricular na rede estadual para a construção do novo currículo considerando as concepções contidas no Parecer CEB/CNE $n^{\circ} 7$ das Diretrizes Curriculares Nacionais Gerais da Educação Básica, na Resolução CEB/CNE n $4 / 2010$ que trata das Diretrizes Curriculares Nacionais Gerais da Educação Básica, além da Resolução CEB/CNE n 7/2010 sobre as Diretrizes Curriculares Nacionais do Ensino Fundamental. Para a construção desse currículo foi instituída uma comissão multidisciplinar através de portaria instituída pelo secretario de educação. Essa comissão está constituída por profissionais das diferentes áreas do conhecimento, e, nela está o ensino religioso.

\section{Ensino Religioso e a Formação de Professores: inicial e continuada}

A partir do novo cenário brasileiro sobre a concepção do ER com a alteração do art. 33 e frente às exigências de formação de professores/as que compreendessem esse ensino no novo enfoque, iniciamos em 1998, a busca por parceria com instituições de ensino superior para possibilitar a abertura de cursos de especialização em ensino religioso, na tentativa de suprir a carência de formação inicial, já que no âmbito estadual não existia curso de graduação - licenciatura em ensino religioso.

Dessa iniciativa, surge uma articulação com o Sindicato dos Trabalhadores da Educação (SINTEAL) para ser o intermediário e parceiro, representante legal junto ao Centro de Educação da Universidade Federal de Alagoas considerando que o proponente era pessoa física e, nesse contexto, os interessados eram os/as professores/as da rede pública de ensino e não pessoa jurídica. Essa foi à alternativa encontrada pela equipe técnica pedagógica do programa de ensino fundamental da Secretaria de Estado da Educação e do Esporte para cuidar da formação de professores/as que pertenciam ao quadro do magistério público estadual e municipal que estavam atuando no ensino religioso.

Com o acordo firmado entre professores/as, universidade, o sindicato ajudounos na administração financeira para o recebimento das mensalidades dos/as cursistas, lembrando que, o investimento financeiro foi de total responsabilidade dos/as professores/as. Para a seleção dos cursistas, os critérios foram, a análise do currículo e a experiência pedagógica na área. 
Essa especialização lato-sensu foi de 360 horas e a elaboração do projeto de autoria e responsabilidade das professoras, Ângela Maria Ribeiro Holanda e Noélia Pereira Capistrano da Secretaria de Estado da Educação e do Esporte e da professora Rosário de Fátima da Silva da Secretaria Municipal de Educação de Maceió.

A referência para a elaboração do projeto seguiu as orientações do Fórum Nacional Permanente do Ensino Religioso e a coordenação do curso pela Prof ${ }^{a}$ Dra. Maria Antonieta Albuquerque de Oliveira, do Centro de Educação da citada Universidade. As disciplinas ministradas: Fundamentos Epistemológicos do Ensino Religioso; Culturas e Tradições Religiosas; Psicologia e Fenômeno Religioso; Teologias; Textos Sagrados: orais e escritos; Seminário de Pesquisa Científica, Metodologia da Pesquisa; Didática do Ensino Religioso; e Ethos no Ensino Religioso, finalizando com a apresentação de trabalho de conclusão de curso, com monografias.

A docência dessa formação foi exercida pelos/as professores/as do Centro de Educação da Universidade Federal de Alagoas e com a participação de dois professores convidados, um da Universidade Católica de Pernambuco - UNICAP - Recife-PE, e outro da Pontifícia Universidade Católica do Paraná. Fomos pioneiros na oferta dessa especialização numa universidade federal, porém, não houve abertura para novas turmas. O projeto dessa especialização foi utilizado em outra especialização numa instituição superior, privada.

Essa formação contribuiu significativamente com a participação dos professores/as na reelaboração da proposta curricular do Estado considerando que as ementas das disciplinas, no curso, sinalizavam as concepções da Lei 9.475/97 e os encaminhamentos estabelecidos pelo Fórum Nacional Permanente do Ensino Religioso.

No ano de 1999, além da construção do referencial curricular houve uma modificação em relação aos trabalhos das equipes do ensino religioso. Essa coordenação deixou de existir nas diferentes instâncias, secretarias, coordenadorias e escolas, passando a compor a equipe técnica pedagógica da secretaria e da coordenadoria, sendo esta, responsável pelas questões referentes à educação como um todo. Por um lado, houve avanço pedagógico e, por outro, as especificidades foram se diluindo. A exigência era para se ter um generalista e não mais um especialista, e essa determinação trouxeram elementos complicadores para a prática pedagógico dos/as professores/as. 
Com isso, a formação ficou falha, complexa e difícil para ser acompanhada e monitorada.

No ano de 2000 a Secretaria Estadual de Educação assume o investimento financeiro na formação de professores/as indicando professores/as das coordenadorias de ensino para a participação do Curso a Distância - Ensino Religioso, Capacitação para um Novo Milênio, promovido pelo FONAPER num total de 40 cursistas. A participação se deu em dois momentos, quando da transmissão pela Rede Vida de Televisão e pela TV Educadora do Paraná, com carga horária de 120 horas-aulas. O referido curso constou de três eixos, distribuídos em doze módulos: Fundamentos Epistemológicos do Ensino Religioso; Objeto de Estudo do Ensino Religioso e o Cotidiano do Ensino Religioso em sala de aula.

Havia uma busca incessante da Secretaria de Educação para o estabelecimento de parâmetros para a definição da formação de professores, habilitação, concepção sobre currículo do ensino religioso e sua inserção na matriz curricular do ensino fundamental e princípios norteadores para a prática pedagógica dessa área de conhecimento, garantindo, assim, a especificidade e o objeto de estudo desse componente curricular.

\section{Concursos Públicos para o Ensino Religioso}

Na tentativa de minimizar a carência de professores/as são promovidos nos anos de 2000 e 2005, dois concursos públicos na esfera estadual para todas as áreas de conhecimento, incluindo o ER. Os editais asseguravam os fundamentos sobre: educação, legislação, língua portuguesa e os aspectos específicos do componente curricular. Com esse procedimento há uma conquista porque aparece a inserção do ER no conjunto dos demais componentes curriculares já que, para o ingresso de professores no serviço público, deva se efetivar através de concurso público de prova e de títulos, conforme preconiza o art. 67 da Lei $\mathrm{n}^{\circ}$ 9.394/96. Se for ensino a competência é do sistema e não da igreja.

Essa iniciativa, considerada positiva deve ser aliada a instituição de uma comissão para acompanhar os editais da empresa responsável pela elaboração das provas, pois a história se repete, todas as questões contidas na prova dizem respeito 
apenas aos aspectos doutrinários da igreja católica sem mencionar o aspecto pedagógico exigido no componente curricular. Indaga-se, então, o concurso destina-se para a atuação de professores/as na escola pública ou para atuação na catequese paroquial? Talvez o equívoco seja a falta de conhecimento por parte das empresas contratadas para esse fim e da própria secretaria de educação.

Para aqueles que se submetem a um concurso público é fundamental a atenção aos editais, observando os equívocos e requerendo em tempo hábil as alterações dos possíveis equívocos a serem observados a partir das legislações vigentes.

\section{Estadualização da Lei $n^{\circ}$ 9.475/1997 nos Sistemas de Ensino}

$\mathrm{Na}$ busca da definição curricular e formativa e dos saberes desenvolvidos em sala de aula, a Secretaria de Estado da Educação e do Esporte de Alagoas, por meio da Gerência de Ensino Fundamental fez uma exposição de motivos solicitando ao Conselho Estadual de Educação providências para regulamentação e definição de políticas de admissão e formação de professores e organização curricular referentes ao ensino religioso.

E, após essa solicitação ocorre uma audiência pública promovida pelo mencionado conselho, em 09 de abril de 2002, no Teatro Linda Mascarenhas, na cidade de Maceió. Essa histórica audiência contou com a presença de representantes de diversos credos religiosos e das equipes pedagógicas, num total de 87 representantes das redes públicas de ensino, 02 representantes da rede privada e 03 entidades não governamentais. Na ocasião foram apresentadas propostas escritas pela Seicho-no-iê do Brasil, regional Maceió/AL., e emendas das equipes de ensino religioso das redes públicas de ensino. Participou desse processo o Conselho Municipal de Educação da cidade de Arapiraca.

Dessa audiência ocorre à estadualização da Lei $n^{\circ}$ 9.475/97 para o ensino religioso no sistema de ensino de Alagoas passando a ser regulamentado pela Resolução CEB/CEE/AL. no 003/2002 e pelo Parecer CEB/CEE/AL. nº 006/2002.

Nessas leis está a definição dos conteúdos curriculares recomendando a sua inserção no Projeto Político Pedagógico da Escola que na sua construção deve promover o conhecimento sobre os seguintes aspectos: 
O fenômeno religioso no contexto da formação social do Brasil; As múltiplas influências que compõem a pluralidade religiosa brasileira; A cosmovisão das sociedades nativas do atual território brasileiro: o fenômeno religioso nessas sociedades; A cosmovisão das sociedades africanas, particularmente dos povos que foram trazidos ao território brasileiro durante o período escravagista: o fenômeno religioso nessas sociedades; A cosmovisão das sociedades européias e particularmente dos povos que ocuparam/imigraram para o território brasileiro: o fenômeno religioso nessas sociedades; A cosmovisão das sociedades orientais, destacando os povos que migraram para o território brasileiro: o fenômeno religioso nessas sociedades; Os valores éticos e morais presentes nas diversas religiões; Religião e identidade; A relação entre as cosmovisões religiosas e científica na contemporaneidade; Liberdade religiosa e tolerância como princípios e valores que fundamentam o Estado Democrático de Direito. (PARECER CEB/CEE/AL nº 006/2002)

E em relação às orientações sobre a formação dos professores/as no sistema estadual de ensino para os anos iniciais do ensino fundamental, os professores deverão ser os formados em magistério, na modalidade normal de nível médio, assim como, os formados em pedagogia, anos iniciais, ou no curso normal superior, recomendando-se, para tanto, inclusão de estudos sobre o ensino religioso. E para os anos finais do ensino fundamental deverá ser os licenciados em história, filosofia, ciências sociais e psicologia ou os licenciados em ensino religioso e portadores de especialização latosensu em ensino religioso ou pós-graduação stricto-sensu na área e mais os bacharéis em história, filosofia, ciências sociais, psicologia e teologia que venham a concluir curso de preparação pedagógica em instituições devidamente credenciadas, nos termos da Resolução CEB/CNE nº 02/97.

A competência para a formação continuada e o desenvolvimento de projetos nessa direção, é atribuída à Secretaria Estadual de Educação e as Secretarias Municipais de Educação. E, a oferta desse ensino, pelas instituições privadas não confessionais é 
opção da proposta pedagógica da escola e independentemente da doutrina religiosa específica que professem, deverá pautar-se nos princípios do respeito e da tolerância para com os que manifestam credos e crenças diferentes ou os que não professam nenhuma crença religiosa, promovendo a convivência pacífica entre as diversas manifestações religiosas que compõem a pluralidade étnica e cultural da nação brasileira.

Com a regulamentação da Lei $n^{\circ} 9.475 / 97$ pela Resolução CEB/CNE $n^{\circ}$ 003/2002 e Parecer CEB/CNE nº 006/2002 as definições ficam mais claras e objetivas facilitando a organização do ensino religioso no sistema estadual de ensino.

Assim, a inserção na matriz curricular, a definição dos conteúdos e o estabelecimento de normas para habilitação dos professores e a admissão são de competência do sistema de ensino. Esses procedimentos estão no mesmo patamar exigido em outras áreas de conhecimento. E, em relação à admissão, os procedimentos estão no Plano de Cargo e Carreiras do Magistério Público Estadual.

Na sequência da caminhada e na linha de formação, acontece no ano de 2003 na cidade de Maceió nas dependências do Colégio INEI, bairro de Ponta Verde, o VIII Seminário de Capacitação Docente para o Ensino Religioso com a temática: O Ensino Religioso, uma área de conhecimento para a formação do cidadão, numa promoção do FONAPER em parceria com associação, sindicatos e instituições de ensino superior, a saber: Secretaria de Estado da Educação e do Esporte, Secretaria Municipal de Educação de Maceió, Faculdade de Filosofia e Teologia de Alagoas (FAFITEAL), Associação de Educação Católica (AEC), Seminário Teológico Batista de Alagoas (SETBAL), Centro de Estudos Superiores de Maceió - CESMAC, Centro de Educação - (CEDU/UFAL), Pró-Reitoria de Extensão e Núcleo de Estudos Afro-brasileiro (CEDU/PROEX/NEAB/UFAL), Conselho Estadual de Educação e Conselho Municipal de Educação de Maceió, Sindicato dos Trabalhadores de Educação (SINTEAL) e Pontifícia Universidade Católica do Paraná, sob a chancela da Pró-Reitoria de Extensão da Universidade Federal de Alagoas UFAL.

O seminário contou com a participação de trezentos e sessenta e dois professores/as de todas as unidades da federação com uma programação contendo palestras e painéis com as temáticas: Elementos constitutivos para regulamentação de 
uma legislação, Diretrizes Curriculares para Formação Docente; Ensino Religioso, um componente curricular e seu fazer pedagógico; Culturas e Tradições Religiosas: um dos eixos temáticos do ensino religioso; $\mathrm{O}$ docente do ensino religioso na formação do cidadão.

$\mathrm{Na}$ sequência de formação de professores foi ofertada pela Secretaria de Educação, através da Fundação, Extensão e Pesquisa - FUNDEPES, no ano de 2006 uma formação de 120 horas aulas estruturada em três etapas de 40 horas-aula, ministrada pelas professoras Ângela Maria Ribeiro Holanda da Secretaria de Estado da Educação e Olímpia Alves Santos da $3^{\text {a }}$ Coordenadoria Regional de Palmeira dos Índios da mesma Secretaria de Educação. Essa formação foi destinada aos/as professores/as do $6^{\circ}$ ao $9^{\circ}$ ano com as seguintes temáticas: $1^{\mathbf{a}}$ etapa: Fundamentos Epistemológicos e Metodológicos do Ensino Religioso; $\mathbf{2}^{\mathbf{a}}$ etapa: Ensino Religioso na Diversidade Cultural Religiosa Brasileira; $3^{\mathbf{a}}$ etapa: Referencial Curricular do Ensino Religioso da Rede Estadual de Ensino.

No Estado de Alagoas todas as redes de ensino seguem as orientações estabelecidas pela Secretaria de Estado da Educação e do Esporte no que se refere ao ensino religioso e aos demais componentes curriculares, exceto a Secretaria Municipal de Educação de Maceió que em 2011 regulamentou, na sua rede, o ER. A lei que dispõe sobre a questão é a Resolução CEB/COMED/AL nº 02/2011. Esta resolução apresenta no art. $6^{\circ}$ parágrafo único os eixos para a revisão da proposta curricular: as culturas e tradições religiosas e a literatura sagrada e símbolos religiosos, "destacando os cultos afro-brasileiros e os indígenas brasileiros". E, para a docência nos anos finais foi inserido os licenciados e bacharéis em Pedagogia; e a formação continuada tem caráter obrigatório sendo ofertada pela Secretaria Municipal de Educação de Maceió com carga horária anual mínima, cumulativa de 40 horas presenciais. Esses são os pontos que diferenciam da Resolução CEB/CEE/AL nº 003/2002.

\section{Considerações}

O Conselho Nacional e Estadual de Educação legisla sobre a matéria, porém ao determinar ações sobre a educação brasileira exclui esse ensino nos documentos 
curriculares e nas políticas para a formação de professores/as. Há uma ausência total dessa abordagem.

E como articular a questão e exigir o tratamento igual do ER aos demais componentes curriculares? Existem as legislações estaduais, mas sozinhas elas não respondem pelos diferentes aspectos. Quem normatiza a educação brasileira é o Conselho Nacional de Educação. E, se esse conselho que reconhece e dá status quo de área de conhecimento a esse componente curricular precisa sinalizar os caminhos a serem percorridos na esfera pedagógica, institucional e acadêmica

O conflito persiste em relação à matrícula facultativa, formação acadêmica e pela inexistência de cursos de licenciatura na área sem contarmos com à atuação de professores de outras áreas ministrando este ensino apenas para complementação da carga horária.

Vários caminhos já foram percorridos, e, em termos legais a partir das legislações atuais há uma compreensão sobre a epistemologia desse ensino, mas na prática não conseguimos exercê-la, mesmo com a aprovação da Resolução CEB/CNE ${ }^{\circ}$ 7/2010 que define as Diretrizes Curriculares Nacionais do Ensino Fundamental atribuindo ao ER status quo de área de conhecimento e as legislações locais.

O conselho nacional e estadual de educação legisla sobre a matéria, porém ao determinar ações sobre a educação brasileira exclui esse ensino nos documentos curriculares e nas políticas para a formação de professores/as. Há uma ausência total dessa abordagem.

E como articular a questão e exigir o tratamento igual do ER aos demais componentes curriculares? Existem as legislações estaduais, mas sozinhas elas não respondem pelos diferentes aspectos. Quem normatiza a educação brasileira é o conselho nacional de educação. E, se esse conselho que reconhece e dá status quo de área de conhecimento a esse componente curricular precisa sinalizar os caminhos a serem percorridos na esfera pedagógica, institucional e acadêmica.

O conflito persiste em relação à matrícula facultativa, formação acadêmica e pela inexistência de cursos de licenciatura na área e devido à atuação de professores de outras áreas ministrando o ensino apenas para complementar a carga horária.

Outro desafio é carência de professores em todas as áreas de conhecimento com a contratação de monitoria para a docência e a falta de uma política de formação 
continuada, além dos conteúdos que são ministrados apenas na linha de valores e cidadania. Essa prática também ocorre nas escolas privadas. O espaço acadêmico não tem oferecido condições e dado respostas para que o/a professor/a desempenhe suas funções conforme a habilitação que lhe foi concedida. E a formação continuada ainda não é considerada uma política para o investimento da melhoria da educação brasileira.

Nem tudo está resolvido. No momento conseguimos a estadualização da lei e a garantia na matriz curricular, e, portanto o status quo de área de conhecimento. A questão é a definição curricular enquanto área de conhecimento.

Sabe-se que o componente curricular ER propicia para a vivência de um espaço formativo de cidadãos/ãs capazes de dialogar, de promover a abertura ao pluralismo, inclusive o religioso e ao convívio respeitoso com o diferente. Aceitar as diferenças e conviver com elas não tem sido uma convivência pacífica. $\mathrm{O}$ respeito à diversidade ainda é uma reivindicação recente e tem sido uma conquista árdua e persistente da sociedade humana.

A partir da Lei $n^{\circ}$ 9.475/97 o ensino religioso passa a ser concebido como parte integrante da formação básica do cidadão, assegurado o respeito à diversidade cultural religiosa do Brasil, vedadas quaisquer formas de proselitismo.

Desta forma é cabível e adequado o pensamento de Carbonari:

[...] o ensino religioso nas escolas deve, antes de tudo, fundamentar-se nos princípios da cidadania e do entendimento do outro. O conhecimento religioso não deve ser um aglomerado de conteúdos que visam evangelizar ou procurar seguidores d doutrinas, nem pode ser associado a imposição de dogmas, rituais ou orações, mas um caminho a mais para o saber sobre a sociedade humana e sobre si mesmo. As religiões são corpos doutrinais de construção histórica, têm contextos vinculados à etnologia, história social, geografia, arte, política, economia etc... Conhecê-las e desvendá-las significa ampliar a rede de conhecimentos dos estudantes sobre o patrimônio cultural humano e, ao mesmo tempo, propiciar-lhes suporte emocional e social do ponto de vista do binômio: autoconhecimento / alteridade (aprender a ser / aprender a conviver). (PARECER CEB/CEE/AL nº 006/2002).

Nesta lógica não cabe ao ER à prática de sedução para conquistar novos adeptos e nem manipular as consciências dos estudantes ou interferir em suas práticas religiosas. Fazer seguidores, prosélitos não é permitido conforme inciso VI do art. $5^{\circ}$ da Constituição Federal de 1988: “é inviolável a liberdade de consciência e de crença, sendo assegurado o livre exercício dos cultos religiosos e garantida, na forma da lei, a proteção aos locais de culto e suas liturgias". E ainda o art. 18 da Declaração dos Direitos Humanos corrobora nesse sentido afirmando: 


\begin{abstract}
"Toda pessoa tem o direito à liberdade de pensamento, consciência e religião; este direito inclui a liberdade de mudar de religião ou crença e a liberdade de manifestar essa religião ou crença, pelo ensino, pela prática, pelo culto e pela observância, isolada ou coletivamente, em público ou em particular”.
\end{abstract}

Constata-se que, o maior desafio é a carência de professores/as graduados na área para desempenhar sua função com competência. E os resultados do processo ensino e aprendizagem são decorrentes, também, da formação inicial e continuada. O caminho para superar dificuldades de concepções e práticas pedagógicas é o investimento na formação continuada, aliada a política de formação dos diferentes componentes curriculares nos respectivos sistemas de ensino.

Assim, os desafios enfrentados para efetivação do ER no Estado de Alagoas são os mesmos dos demais componentes curriculares dos diferentes estados da federação. Para reverter à situação há necessidade de iniciativas para a implantação/implementação de políticas para a formação inicial e continuada de acordo com as políticas estabelecidas nos termos legais, considerando que as orientações já estão consolidadas nas resoluções e pareceres nacionais e estaduais. Essa iniciativa certamente é de competência dos sistemas de ensino.

Referenciais

ALAGOAS. Estatuto do Conselho do Ensino Religioso da Arquidiocese de Maceió. Diário Oficial de 31 de maio de 1944.

ALAGOAS. Decreto Lei no 2.937, de 29 de maio de 1944. Dispõe sobre o ensino religioso nos estabelecimentos de instrução primária do Estado de Alagoas. Diário Oficial do Estado, em 31 de maio de 1944.

ALAGOAS. Resolução n. 08 de 06 de março de 1976. Disciplina o ensino religioso no Estado de Alagoas. Conselho Federal de Educação. Diário Oficial do Estado, Maceió, 1976.

\title{
ALAGOAS. Programa Mínimo da Confissão Católica para o Ensino Religioso do
} $1^{\circ}$ Grau, no Estado de Alagoas. Maceió: Imprensa Universitária da Universidade Federal de Alagoas, 1977.

ALAGOAS. Decreto Governamental $\mathbf{n}^{\circ}$ 5027. Introduz o ensino religioso, de matrícula facultativa, no currículo de $1^{\circ}$ e $2^{\circ}$ graus das escolas da rede estadual de ensino. Palácio Marechal Floriano Peixoto. Maceió, março de 1982.

ALAGOAS. Sistemática para Orientação do Ensino Religioso. Secretaria da Educação: Maceió: 1985. P.23.

ALAGOAS. Proposta Curricular do Ensino Religioso do Estado de Alagoas. Secretaria de Educação de Alagoas. Maceió: SERGASA, 1988. 
ALAGOAS. Referencial Curricular para o Ensino Religioso - Versão Preliminar. O Esporte. Secretaria de Estado da Educação e do Esporte. Maceió, 1999 p. 1-30.

(Mimeo).

ALAGOAS. Resolução no 2, de 04 de agosto de 2011. Regulamenta a oferta do ensino religioso na rede municipal de ensino de Maceió. Conselho Municipal de Educação de Maceió. Diário Oficial do Município, 2011.

ALAGOAS. Resolução no $\mathbf{0 0 3}$, de 4 de julho de 2002. Regulamenta o art. 33 da Lei 9.394/96 alterado pela Lei 9475/97 no âmbito do Sistema Estadual de Ensino de Alagoas e define normas correlatas. Câmara de Educação Básica. Conselho Estadual de Educação. Diário Oficial. Maceió, 2002.

ALAGOAS. Parecer n. 006, de 4 de julho de 2002. Regulamenta o art. 33 da Lei 9.394/96 alterado pela Lei 9.475/97 no âmbito do Sistema Estadual de Ensino de Alagoas. Conselho Estadual de Educação de Alagoas. Câmara de Educação Básica. Diário Oficial do Estado, Maceió, 2002.

BRASIL. Fórum Nacional Permanente do Ensino Religioso. Parâmetros Curriculares

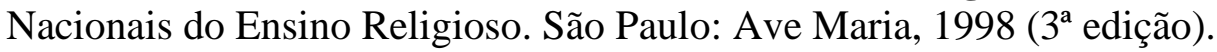

BRASIL. Constituição da República Federativa do Brasil. Brasília: Diário da União n $191-A, 1988$. In OLIVEIRA, Juarez de (Org. dos textos, notas e índices). Série

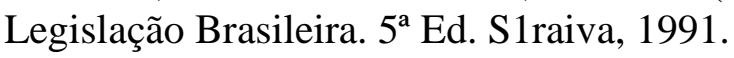

BRASIL. Lei n. 9.394/96, de 20 de dezembro de 1996. Estabelece as diretrizes e bases da educação nacional. Diário Oficial da República Federativa do Brasil. Poder legislativo, Brasília, DF, 23 dez 1996.

BRASIL. Diversidade Religiosa e Direitos Humanos. Secretaria Especial dos Direitos Humanos. Brasília: DF, nov./2004.

BRASIL, Lei n ${ }^{\circ}$ 9.475, de 22 de julho de1997. Dá nova redação ao art. 33 da Lei n ${ }^{\circ}$ 9.394, de 20 de dezembro de 1996, que estabelece as diretrizes e bases da educação nacional. Disponível em: <http://www.planalto.gov.br/ccivil_03/Leis/L9475.htm>.

Acesso em: out. 2010.

BRASIL. Resolução CEB/CNE $\mathbf{n}^{\mathbf{0}}$ 7, de 15 de dezembro de 2010. Fixa Diretrizes Curriculares Nacionais para o Ensino Fundamental de 9 (nove) anos. Diário Oficial da União, Brasília, 2010, Seção 1, p. 34.

BRASIL. Resolução CEB/CNE $n^{\circ}$ 4, de 14 de julho de 2010. Define Diretrizes Curriculares Nacionais Gerais para a Educação Básica. Diário Oficial da União, Brasília, 2010, Seção 1, p. 824.

Recebido: $13 / 02 / 2013$

Received: 02/13/2013

Aprovado: 04/07/2013

Approved: 07/04/2013 